\title{
Questions from the American Board of Family Practice Diplomates Regarding Maintenance of Certification Program for Family Physicians (MC-FP)
}

By the time this issue of the Fournal of the American Board of Family Practice has been published, the ABFP will have distributed to its Diplomates an overview of the MC-FP and a "Frequently Asked Questions" supplement. Those Diplomates who have certified/recertified in July 2003 and December 2003 will be the first wave to enter the MC-FP cycle on January 1, 2004. For more information regarding the MC-FP, please visit our website at http://www.abfp.org. Since the introduction of MC-FP, the Board has received a number of questions from family physicians in the field. Below are some of these questions with answers from James C. Puffer, MD, ABFP Executive Director.

\section{Question From Diplomate Practicing Emergency Medicine}

Q

My concern is the peer review portion of the new requirements. I am solo and do not bave a call partner. I might find someone to cover for me twice a year, but I do not have any peers that can vouch for my care. I believe the specialists that we refer to are in a better position to evaluate our work than peers are, at least in the solo setting. My certification expires in 2007. Please let me know your thoughts.

A The specialists to whom you refer patients would indeed be suitable peers to evaluate you. We anticipate that it will be 1 to 2 years before this component of the MC-FP is ready to come on-line, but when it does, you should have no problem meeting the requirements using any physician colleagues that you would like to chose. Because your certification expires in 2007, you will not enter the MC-FP cycle until January 1, 2008.

\section{Question from a "Process B" Diplomate}

$\mathrm{Q}$

While I await the outcome of the fuly 11 examination, I am curious how "Process B" Diplomates like me will be able to meet the new MC-FP requirements. I originally certified with the ABFP in 1985 and have subsequently gone the "Process B" route in 1991, 1997, and again in 2003 because I practice in an occupational medicine setting. Consequently, chart review requirements bave made "Process $A$ " unviable, because I am not actively managing such cases as breast cancer, congestive beart failure, or byperthyroidism.

A We are developing unique Part IV components (eg, Patient Safety, Systems-Based practice) that will give all our Diplomates who previously certified under Process B the opportunity to continue to do so. You will be hearing more about these when they come on-line in January 2005.

\section{Question from FP in Kenya}

$Q$ Today I received documents from the ABFP about the new Maintenance of Certification program for American Family Physicians. I applaud the Board's attempt to assure competence and quality in our specialty. However, I have some personal concerns and questions. I am a Board-certified (and recertified) family physician who maintains an active medical license in the state of Kentucky, even as I work as a full-time missionary doctor in rural Kenya. What mechanisms will the ABFP have to help me "stay current," even when I am out of the United States most of the time? I have been able to secure the required number of CME bours through various distance courses. I have been eligible to keep my "certification" each time I have "recertified" by following "Process B" (the same examination that the new residents take on certification). What 
will this new process of "Maintenance of Certification" mean to me? Are there mechanisms to accommodate my situation? Thank you for your attention to this question. I am certain that I am not the only American Family Physician who is in this situation.

A Thank you very much for your letter. You will be able to keep abreast by participating in MC-FP via the web from Kenya. The Self-Assessment Modules (SAMs) can be taken on-line, and you will receive credit toward your 300-hour CME requirement for the time spent completing these. We will have unique components for Part IV (eg, patient safety) for those who do not have continuity patients. You will be able to continue to recertify just as you have done in the past using Process B.

\section{From a Hospital Family Practice Department}

\section{Q ... Basically, our questions are of necessity and expense. Frankly speaking, many of us are struggling to find ways of cutting expenses. Personally, I think the idea has merit, but I really do not know if I can afford any more expenses. My department members concur that the MC-FP program may be valuable, but question if this is the time to add new burdens to those already facing them.}

A We are fully cognizant of the pressures confronting family physicians. We have designed the MC-FP so that it would take no more time than our current recertification process. The only difference is that we will be asking you to participate in selected components on a regular basis (namely, the Self-Assessment Modules in Part II). The actual amount of time that you spend completing these modules, as well as the Performance in Practice
Modules in Part IV, will be credited toward your 300-hour CME requirement, and you will be able to do these from a computer in your home or office. This will offset some of the cost and time that you would have spent to obtain $\mathrm{CME}$ under the current recertification process.

We anticipate that the cost associated with delivering MC-FP over the web will be more than offset by the savings realized by CME offsets for completing Parts II and IV. In addition, there will be fewer costs associated with travel, lodging, and lost opportunity income from practice associated with taking the recertification examination at a limited number of written test centers on a single day (by 2005, we will be offering the examination by computer at more than 200 sites and on multiple dates). By the time that you figure in these savings, you will find that your cost of participating in MC-FP may be LESS than the actual costs incurred to recertify using the current process.

We do believe that MC-FP will be a valueadded activity for you and your colleagues. Clear evidence exists that physician reimbursement in the future is going to be tied to quality. The Center for Medicare Services is readying a pilot program to base reimbursement on performance measured against quality indicators. The private insurers will not be far behind. We expect that participation in MC-FP will satisfy these requirements as well as those that are being discussed by several state licensure boards regarding relicensing examinations by specialty.

We thank all the Diplomates who have contacted us for sharing their thoughts and concerns. We encourage you to continue to provide us with suggestions on how we can make this process work best for you. 